\title{
SOBRE EL CONOCIMIENTO DE LA MATERIA
}

MAURICIO BEUCHOT

Universidad Nacional

Autónoma de México

En un artículo muy sugestivo y cuestionante, Moulines delata nuestro desconocimiento de la materia, refiriéndolo a los propios materialistas. (Cf. C. U. Moulines, "Por qué no soy materialista", 25-37.) En lo que sigue me propongo (i) destacar algunos rasgos de la argumentación de Moulines, (ii) relacionar su postura respecto al conocimiento de la materia con la postura de Aristóteles -consciente de las diferencias, a pesar de las semejanzas-, y (iii) en vista de la postura aristotélica, presentarle una dificultad.

1. Analizando la argumentación de Moulines, y en un paso previo a su ejercicio explícito, se nos presentan tres tipos de materialistas y, correlativamente, tres tipos de gente que cree saber lo que es la materia: (a) los legos, (b) los científicos y (c) los filósofos. Ciertamente son varios los materialismos que se profesan en cada uno de estos grupos. Con todo, sus argumentos parecen dirigirse a los científicos y a los filósofos. También aquí habría que distinguir entre filósofos que resultarían legos en el campo de la ciencia, y científicos que serían legos en cuanto a la filosofía. Y, obviamente, entre filósofos científicos y científicos filósofos. Tal vez los destinatarios del discurso de Moulines serían todos ellos, cada uno en su medida. Esto nos hace ver que la palabra "materia" (al igual que "ciencia", "filosofía" y muchas otras) es polisémica; que tiene diversos significados en diferentes ámbitos de utilización pragmática (en diferentes contextos históricos) y que, por lo mismo, el problema de la materia corre el riesgo de ser homogeneizado y de no estar claramente planteado. 
Pero, en definitiva, parece ser que Moulines se dirige al filósofo que toma en cuenta la ciencia.

Así, su tesis o conclusión anti-materialista ostenta, como premisa principal y fuerte, que el conocimiento científico actual no nos permite hacernos la ilusión de saber a ciencia cierta lo que es la materia. Lo cual nos mueve a abstenernos de decir que todo es material (i.e. " $(x) P x$ ", donde " $P$ " es el predicado "ser material", con carácter de omni-amplectente) o, en otras palabras, que la realidad es la materia. No porque Moulines no simpatice con el materialismo, sino porque le parece inconsistente y muy deshonesto decir que toda la realidad es algo que no se sabe lo que es (lo cual se estaría haciendo al declarar que todo es materia). Es más loable aceptar que la ciencia no ha podido explicarnos, hasta el presente, lo que es la materia; y, así, no permite el reduccionismo que los materialistas pretenden, casi siempre basados en la autoridad del científico. Pero si presionamos al científico planteándole preguntas decididamente ontológicas -filosóficas - sobre su concepción de la materia, no sabrá qué responder, o sus respuestas serán cada vez más misteriosas. De esto pasa Moulines a una tesis antireduccionista o antimonista, es decir, a la postulación del pluralismo ontológico, a saber, que la realidad posee diversas propiedades fundamentales mutuamente irreductibles. Hay que excluir el dogmatismo de la materia y abrir las perspectivas a una visión pluralista del ente, de la realidad. Por lo menos en tanto que la ciencia no demuestre lo contrario.

Con instrumentos conceptuales diferentes, los científicos y los filósofos han llegado a hablar de la materia. Pero es curioso notar que aun entre los filósofos hay quienes han manifestado un cauteloso agnosticismo, respecto a la materia, algo semejante al que profesa Moulines. Tal es el caso de Aristóteles. No debe perderse de vista la advertencia de que Aristóteles no responde a una pregunta idéntica a la que se plantea Moulines, dado que lo que el estagirita entendía por "materia" y buscaba con ese nombre es harto distinto; sin 
embargo, vale como un ejemplo alterno de modelo filosófico, es decir, de plantear un problema filosófico e investigarlo con medios filosóficos. Además, Aristóteles no poseía, indudablemente, un conocimiento científico como el actual; pero tenía una clara delimitación de la episteme en la que se ubicaba, cosa que no parece que pueda decirse de la ciencia actual (con respecto a la cual cabría más bien hablar de diferentes concepciones de la ciencia, de diferentes concepciones de la filosofía, de diferentes "filosofías" de las "ciencias", etcétera). Por lo demás, en cuanto a la visión filosófica de Aristóteles y a su argumentación sólida, me parece que puede tomarse como una respuesta valiosa al problema. $Y$ creo que ofrece elementos de juicio relevantes para contrastarlos con el "agnosticismo" materialista de Moulines. La diferencia principal radica, a mi parecer, además de la consabida ruptura histórica y cultural, en que el agnosticismo de Moulines es mitigado; por eso tal vez no le cuadre bien el apelativo de "agnóstico materialista", pues su agnosticismo sería en todo caso "de momento", esto es, relativo al estado actual de la ciencia, mientras que el agnosticismo materialista de Aristóteles es de principio: por su misma naturaleza, la materia radical de cada cosa (la que llama "materia prima") es incognoscible, aunque la inferimos como existente en las cosas (a fuer de coprincipio de las mismas, haciendo pareja con la forma substancial), a partir de las operaciones y propiedades sensibles de las cosas mismas. Habla de la materia indirectamente, in obliquo, infiriendo desde el "comportamiento" de las cosas lo que se puede decir de ella. Y se manifiesta en su discurso más negativo (apofático) que afirmativo (katafático), recurriendo siempre al procedimiento epistemológico de la analogía.

2. La tesis de Moulines acerca del desconocimiento factual de la materia nos mueve a procurar una comparación con la tesis de Aristóteles acerca de la incognoscibilidad de principio de la materia. Y, a pesar de que ambos entienden cosas muy diversas por la palabra "materia", a cuestionar inclusive el 
alcance de la tesis de Moulines. Para ello es preciso reconstruir brevemente la argumentación aristotélica.

Ante todo, Aristóteles comienza poniendo buen cuidado en declarar que la noción de materia no es unívoca, sino analógica. Hay dos tipos de materia, que denomina materia prima y materia segunda. La materia segunda —resulta más fácil comenzar por ella- es el cuerpo sensible, cuyas propiedades y operaciones analiza el científico. Mientras que la materia prima es algo más fundamental, y es uno de los coprincipios constitutivos del cuerpo.

Al conocimiento del cuerpo (o materia segunda) accedemos de manera directa, empíricamente. Al conocimiento de la materia prima no podemos acceder empíricamente, sino por inferencia, i.e. por argumentos que prueban su existencia, que indican la necesidad de que el cuerpo esté constituido no sólo de una forma substancial, sino - junto con ella- de una materia prima. $\mathrm{Y}$ a través de las propiedades de la forma substancial del cuerpo es como podemos decir algo - negativa y oblicuamente- acerca de los caracteres de la materia.

De esta manera, de las propiedades esenciales y accidentales del objeto inferimos, según las exigencias del sistema de Aristóteles, la existencia de la materia prima o primera; la cual no se reduce a una entidad abstracta postulada, sino que es un principio inmanente a las cosas; no se reduce a lo que algunos han llamado "individuo vacío" (cf. M. Beuchot, "Ontología y universales en Gustav Bergmann", 43-44), pues éste es concebido como una cosa, y Aristóteles no concibe la materia como una cosa, sino como un principio de la cosa (cf. M. Beuchot, "Estructura y función de la metafísica según Aristóteles", 187). Pues de suyo, en sí misma, la materia es

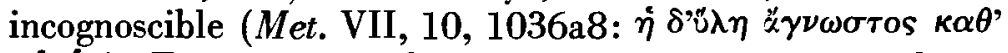
$\left.\alpha v i \tau \eta^{\nu}\right)$. Tampoco se reduce a un noúmeno que está detrás de lo fenoménico. Se manifiesta de alguna manera (Met. VII, 3, 1029a32: $\varphi \alpha \nu \epsilon \rho \dot{\alpha} \delta \dot{~} \pi \omega s \kappa \alpha i \dot{\eta} \ddot{v} \lambda \eta)$. No se puede conocer directamente, pero se puede conocer indirectamente, por una relación de analogía con la forma substancial 


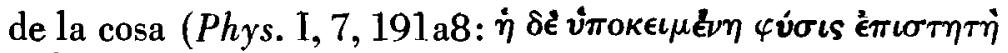
$\kappa \alpha \theta^{\prime} \dot{\alpha} \nu \alpha \lambda \sigma \gamma(\alpha \nu)$.

Podemos reconstruir el razonamiento o argumentación de Aristóteles. (a) Lo que hay son cosas concretas y experimentales. (b) Pero incluyen como constitutivos principios que, aun cuando no son empíricos, sino inteligibles, son reales. Tales son los principios de potencia y acto, que en el caso del cuerpo sensible son la materia y la forma. (c) Si se acepta $(b)$, se llega a que la materia y la forma, aunque no son constatables empíricamente, son exigidos por la comprensión intelectiva de la cosa, a saber, tiene un principio potencial y otro actual. El principio potencial o sustentante es la materia, y el principio actual y determinante es la forma. $(d)$ Ya que se infieren a partir de lo sensible y, de acuerdo con $(a)$, son constitutivos reales de las cosas concretas - y no cosas completas dichos constitutivos-; aunque son entidades inferidas, no son entidades ideales, sino entidades (coprincipios) reales que se descubren por inferencia a partir de la dualidad potenciaacto aplicada al ente sensible. No es un mero pasar de lo gnoseológico a lo ontológico, sino que el argumento se da en el ámbito ontológico, sin salir de él; no es una exigencia de la cosa para ser conocida - como muchos han interpretado-, sino una exigencia del ser de las cosas, de la misma cosa real para existir.

Después de estas cautelas en cuanto al conocimiento que tenemos de la materia —en cuanto a su cognoscibilidad sólo indirecta-, Aristóteles aporta dos definiciones de la materia, aproximativas e in obliquo, más apofáticas que positivas.

La primera definición trata de establecer la materia como substrato o sujeto de las mutaciones del cuerpo: "Llamo 'materia' al sujeto primario de cualquier cosa, a partir del cual, como constitutivo, se produce algo de manera no accidental"

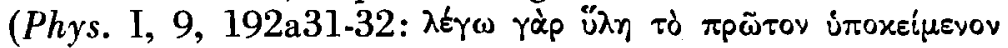

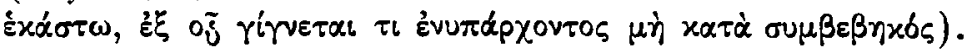

El argumento que aduce Aristóteles para asentar esta consideración lo toma de las mutaciones substanciales. Cuando 
sucede un cambio substancial, la cosa no se destruye, aunque muda de formalidad; la formalidad anterior es suplantada por otra; pero esta permanencia sólo es posible si hay un principio común a la naturaleza que subyace a dicha mutación; por tanto, es necesario que se dé ese principio, el cual es la materia prima.

De aquí se siguen dos cosas. En primer lugar, que no es algo que existe separado de la forma substancial propia del cuerpo en cuestión, sino que entra en combinación con ella. Por eso no sólo es un principio, sino un coprincipio. Y si es un coprincipio o constitutivo, no es un ente completo, sino un elemento del ente. En segundo lugar, ya que es el substrato primario o último que subyace a las mutaciones substanciales, él mismo no cambia, i.e. no está sujeto a la generación ni a la corrupción; es inengendrado (o ingenerable) e incorruptible: "Si el substrato se engendrara, debería existir otro sujeto primero del que se engendrara como de algo constitutivo; pero esto es la naturaleza misma [i.e. la misma materia prima]; por lo cual, existiría antes de ser engendrado (...). Y si se corrompiera, se reduciría a eso último [i.e. a la misma materia]; por lo cual, estaría corrompido antes de corrom-

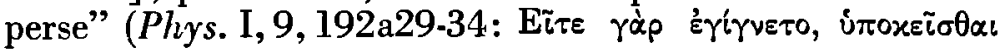

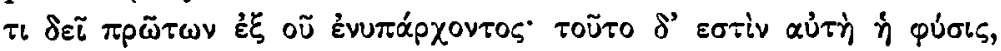

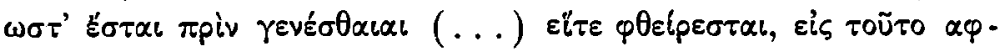

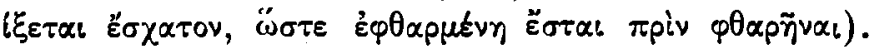

La segunda definición que da Aristóteles de la materia es negativa, como potencia pura: "Llamo 'materia' a lo que en sí mismo no es ni algo [substancial], ni cantidad, ni ninguna de aquellas cosas por las que es determinado el ente" (Met.

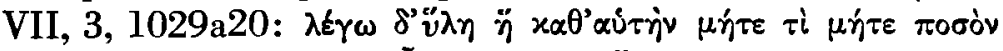

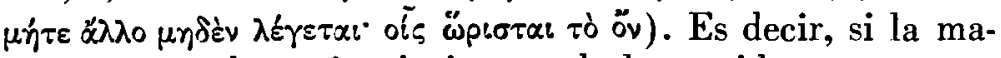
teria no es substancia ni ninguno de los accidentes, no puede ser algo actual, sino meramente potencial. Es oportuno aclarar aquí que no se reduce esta potencialidad a la posibilidad lógica, sino que es potencia ontológica, en el sentido 
aristotélico: aquello que hace posible el ser de una cosa. Pero, como se ha visto, de la materia no se puede decir lo que es, sino más bien lo que no es. Sólo podemos hablar de ella indirecta o negativamente, lo cual nos revela su incognoscibilidad de principio.

3. Y por ello quisiera plantear a Moulines, en vista de la postura aristotélica que ha sido considerada, la siguiente dificultad: ¿Se debe dudar de que conozcamos la naturaleza de la materia porque la ciencia no ha llegado a revelarla, o porque, ontológicamente, la materia es incognoscible en principio? Tomando como hilos de argumentación los descubrimientos científicos actuales sobre la estructura de los cuerpos (a nivel microfísico) y la hipótesis interpretativa de Patrick Suppes, Jesús Mosterín ("Materia y atomismo", passim) considera que la teoría aristotélica de la materia-forma (hylemorfismo) se va configurando como la hipótesis más aceptable (en contra del atomismo clásico) para sustentar los hallazgos de la nueva física, así como la tendencia a ver las cosas como sistemas compuestos de elementos - materia-y estructura - forma- a múltiples niveles. Con lo cual se rescata el concepto aristotélico de materia, y no el del atomismo, como el más próximo a la física de hoy (sin exagerar, por supuesto, en cuanto que se excluyen los detalles de la física aristotélica, arcaica y hasta "mitológica", por lo demás). Y llega a una postulación sorprendente - al menos para los devotos de la ciencia-: "El concepto de materia no es un concepto científico, sino filosófico. No es un concepto primitivo ni derivado de ninguna teoría científica - como lo son, en cambio, los de masa, entropía o leptón-". Si se acepta como concepto filosófico, ¿será vigente la tesis filosófica de Aristóteles acerca de la incognoscibilidad intrínseca de la materia?

\section{BIBLIOGRAFIA}

Aristóteles, Opera, ed., I. Bekker, Berlin: Reimer, 1831.

Beuchot, M., "Ontología y universales en Gustav Bergmann", Crítica, vol. XI, n. $33(1979)$. 
Beuchot, M., "Estructura y función de la metafísica según Aristóteles", Libro Anual del ISEE, vol. VIII (1980).

Mosterın, J., "Materia y atomismo", Ponencia en el Tercer Coloquio Nacional de Filosofía, Puebla, México, 1979.

Moulines, C. U., "Por qué no soy materialista", Crítica, vol. IX, n. 26 (1977). 